\title{
1.2 GBit/s Pseudo Random Pulse Generator Using Multiplexing with GaAs Mesfet Gates
}

\author{
Hede, Carsten
}

Published in:

8th European Microwave Conference

Link to article, DOI:

10.1109/EUMA.1978.332564

Publication date:

1978

Document Version

Publisher's PDF, also known as Version of record

Link back to DTU Orbit

Citation (APA):

Hede, C. (1978). 1.2 GBit/s Pseudo Random Pulse Generator Using Multiplexing with GaAs Mesfet Gates. In 8th European Microwave Conference (pp. 66-70). IEEE. https://doi.org/10.1109/EUMA.1978.332564

\section{General rights}

Copyright and moral rights for the publications made accessible in the public portal are retained by the authors and/or other copyright owners and it is a condition of accessing publications that users recognise and abide by the legal requirements associated with these rights.

- Users may download and print one copy of any publication from the public portal for the purpose of private study or research.

- You may not further distribute the material or use it for any profit-making activity or commercial gain

- You may freely distribute the URL identifying the publication in the public portal

If you believe that this document breaches copyright please contact us providing details, and we will remove access to the work immediately and investigate your claim. 
1.2 GBit/s PSEUDO RANDOM PULSE GENERATOR USING

MULTIPLEXING WITH GaAS MESFET GATES

Carsten Hede*

\section{ABSTRACT}

A 1.2 Gbit/s RZ pseudo random bit generator using multiplexing of six $200 \mathrm{Mbit} / \mathrm{s}$ channels, and a GaAs-MESFET gate circuit which exhibits both high speed and simplicity are presented.

As a new contribution to the treatment of pseudo random sequences it is shown how the autocorrelation function and the Fourier spectrum of a sequence obtained by multiplexing are distorted. These functions may be shaped to a desired form by proper choice of mutual delays of sequences contributing to the multiplexing.

\section{INTRODUCTION}

In many fields, such as optical communication, radar technique, and digital data processing, there is an increasing need for subnano second electronics. At present much progress is achieved in gigabit/s logic and many different approaches are under investigation [1].

A useful tool in fast electronics is the pseudo random pulse generator where the bit sequence is generated in a shift register with appropriate feed back connections. Pseudo random sequences generated in this way have suitable properties for testing and evaluation of communication systems [2].

In the laboratory the integrated technique has entered the sub-nano second region [3], but such fast circuits are not yet commerically available. Consequently, pesudo random generators for applications in the gigabit range cannot be built using standard integrated elements. One way to overcome this problem is to multiplex a number of pseudo random sequences generated at a lower frequency. The drawback of this technique is that the autocorrelation and spectral properties of a multiplexed sequence is somewhat degraded compared to those of the individual shift register sequences.

The technique of multiplexing sequences has been demonstrated using bipolar transistors [4] and step recovery diodes [5], [6]. This paper presents a new and very simple approach using a hybrid GaAs-MESFET gate circuit which may be regarded as a hybrid, analog version of the gates used in integrated techniques [7]. The GaAs-MESFET is a very fast component and offers simplicity in circuitry compared to, for instance, bipolar transistors.

A bit rate of $1.2 \mathrm{Gbit} / \mathrm{s}$ is achieved by multiplexing six $200 \mathrm{mbit} / \mathrm{s}$ bit streams.

The paper will describe first the total system, then the FET-gate. Finally, the autocorrelation and spectral properties of multiplexed sequences will be treated.

* Electromagnetics Institute

Technical University of Denmark

DK 2800 Lyngby, Denmark 


\subsection{BLOCK DIAGRAM}

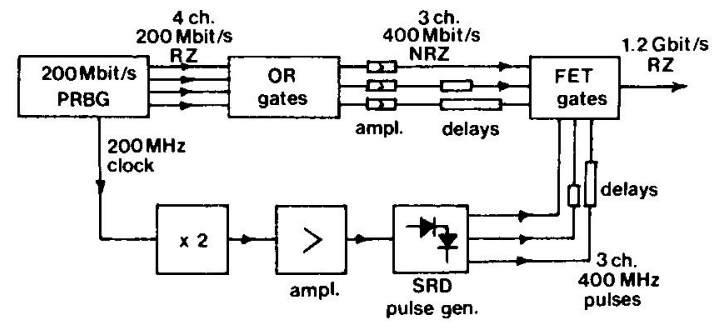

Fig. 1: Block diagram of 1.2 Gbit/s pseudo random pulse generator.

Fig. 1 shows the block diagram of the generator. A $200 \mathrm{Mbit} / \mathrm{s}$ sequence is generated by an ll section ECL shift register generator, which delivers four channels that axe delayed versions of the same sequence. These four $200 \mathrm{mbit} / \mathrm{s} \mathrm{RZ}$ channels are combined to three $400 \mathrm{Mbit} / \mathrm{s}$ NRZ channels as shown in fig. 2 . Standard ECL OR-gates are used. with different delays in order to allow for time multiplex, these three channels are fed into a FETgate circuit. Here each $400 \mathrm{mbit} / \mathrm{s}$ NRZ signal modulates a $400 \mathrm{MHz}$ narrow pulse stream obtained from the 200 $\mathrm{MHz}$ clock signal of the shift register generator. This clock signal is frequency doubled, amplified, and converted into a narrow pulse stream using step recovery diodes. The outputs from the FET-gate circuit are three $400 \mathrm{Mbit} / \mathrm{s} \mathrm{Rz}$ pulse streams. These are finally combined to a $1.2 \mathrm{Gbit} / \mathrm{s}$ signal in a Schottky barrier diode passive OR-gate.

Fig. 2: ECL OR combiner. generator. The GaAs MESFETs used, had saturation currents below $15 \mathrm{~mA}$. Using transistors with high-

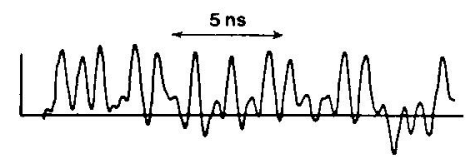
er saturation currents a cleaner output signal can be obtained because the Schottky-barrier diodes in the final oR-gate working into $50 \Omega$ will at a higher voltage level

Fig. 3: Output from $1.2 \mathrm{Gbit} / \mathrm{s}$ be closer to ideal diodes.

\subsection{GaAs-MESFET GATE CIRCUIT}

The GaAs-MESFET has earlier been investigated for high speed switching [7] [8]. Performance at $4 \mathrm{GHz}$ has been demonstrated [3]. The extreme speed offered by this component makes it very simple to apply in circuits at least in the lower Gbit/s range.

The GaAs-MESFET gate circuit presented here consisted of three single gates. Fig. 4 shows the simple configuration of a single FET-gate.

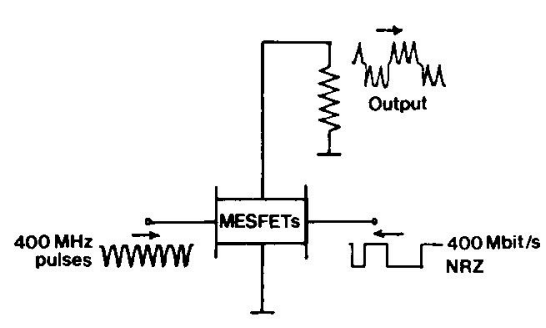

Fig. 4: GaAs-MESFET AND-gate.
Fig. 5: Performance of a GaAs-IIESFET

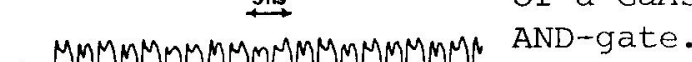

(a) PMPMMPMMMPMp (a) $400 \mathrm{MHz}$ pulse

(b)<smiles>CCCCCCCCCCCCCCCCCCCCC</smiles>

(b) $400 \mathrm{Mbit} / \mathrm{s} \mathrm{NRZ}$ logic input.

(c) Modulated pulse output. 
Two MESFETs are coupled in parallel and are driven in the saturation region. They act as nearly ideal current sources. Thus, the output voltage is the inverted sum of the two input voltages. Fig. 5 shows a test of a MESFET gate. The low shifted pulses in the output signal are removed by the final schottky-barrier oR-gate.

The FETs used were chips bonded directly into a microstrip circuit.

\section{AUTOCORRELATION AND SPECTRA OF MULTIPLEXED SEQUENCES}

In this work, multiplexing is performed as an addition of time signals as illustrated in fig. 6 for the case of three sequences. It will be assumed that the sequences contributing to the multiplexing are identical,

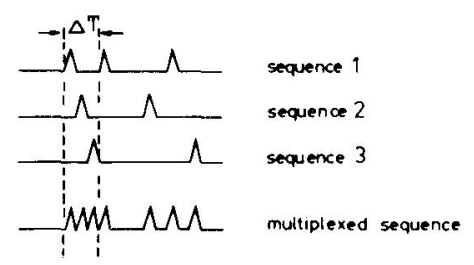

Fig. 6: Multiplexing of sequences. i.e. are mutually delayed versions of the same sequence.

\subsection{AUTOCORRELATION}

The digital autocorrelation function, $\rho$ (i) [2], for a maximal length shift register sequence is illustrated in fig. 7. It has the value $-1 / \mathrm{N}$ except of course for $i=\mathrm{pN}$, where $\mathrm{p}$ is an integer and $\mathrm{N}$ is the bit sequence length.

Consider the multiplexing of two sequences. The mutual time shift must be an odd number of half clock periods; let it be $(2 \mathrm{p}+1) \frac{\Delta \mathrm{T}}{2}$, where $\Delta \mathrm{T}$ is the clock period. For the multiplexed sequence, $\rho(i)$ will have the period $2 \mathrm{~N}$ and assume the same values as for a single

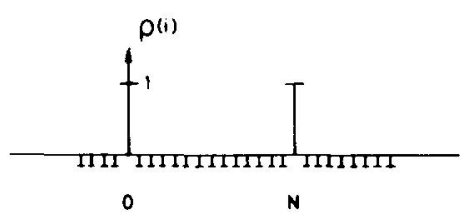

Fig. 7: Digital auto correlation function of maximal length sequence. sequence except for a few special i-values. For $i=2 p+1$, the calculation of $\rho(i)$ will partly be a correlation of the original sequence with itself. The same is true for $i=2 \mathrm{~N}-2 \mathrm{p}-1$. Thus $\rho(2 \mathrm{p}+1)$ and $\rho(2 \mathrm{~N}-2 \mathrm{p}-1)$ will be large and the periodicity implies two extra peaks in each period of the autocorrelation function. This is illustrated in fig. 8.

If three or more sequences are multiplexed, more $\rho(i)$ 's will be different from $-\frac{1}{N}$. Some of these special i-values may coincide. Fig.

9 illustrates the case of multiplexing three sequences where two pairs of special i-values coincide.

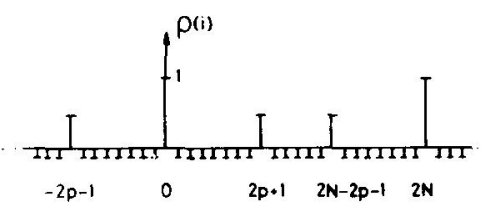

Fig. 8: Autocorrelation function for multiplexing of two sequences.
The autocorrelation function of a multiplexed sequence has a slightly smaller resemblance to that of a truly random sequence than does the autocorrelation function of a single shift register sequence. The actual pattern of degradation is a function of sequence delays and may be shaped by properchoice of these delays.

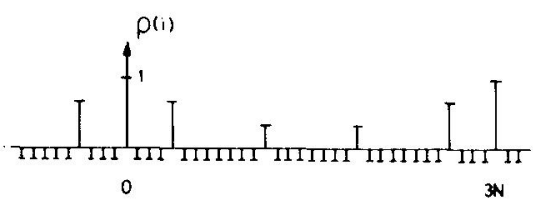

Fig. 9: Autocorrelation function for multiplexing three sequences. 


\subsection{SPECTRUM}

The Fourier power spectrum of a maximal length shift register sequence is similar to that of a truly random sequence. Both have the same envelope and possibly single larger components at the clock frequency and its harmonics. However, due to the signal periodicity the shift register sequence spectrum is discrete. The amplitude spectrum envelope and discrete components of sequence 1 in fig. 6 is shown in fig. $10 . F(n)$ is the component at frequency $n / T ; T$ is the sequence period.

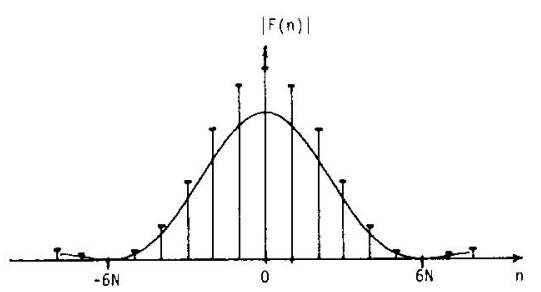

If three such sequences are multiplexed as illustrated in $\mathrm{fig} .6$, with delays of sequence 2 and sequence 3 with respect to sequence 1 of $\left(3 p_{2}+1\right) \frac{\Delta T}{3}$ and $\left(3 p_{3}+2\right) \frac{\Delta T}{3}$ respectively, then the Fourier spectrum of the multiplexed sequence is given by

Fig. 10: Fourier spectrum of pseudo random sequence.

$$
F_{S q}(n)=F(n)\left(1+e^{-j n \frac{2 \pi}{T}\left(3 p_{2}+1\right) \frac{\Delta T}{3}}+e^{-j n \frac{2 \pi}{T}\left(3 p_{3}+2\right) \frac{\Delta T}{3}}\right)
$$

That is, the spectrum is distorted due to the multiplexing. Fig. II $(a+b)$ shows examples of distorted spectra.

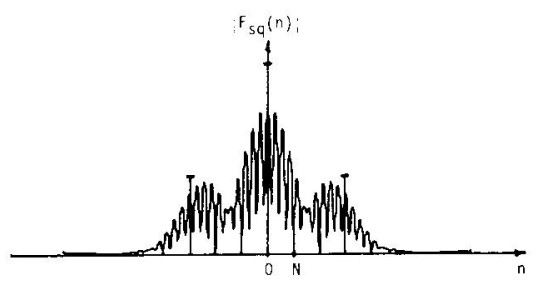

Fig. 11: Spectra distorted by multiplexing.

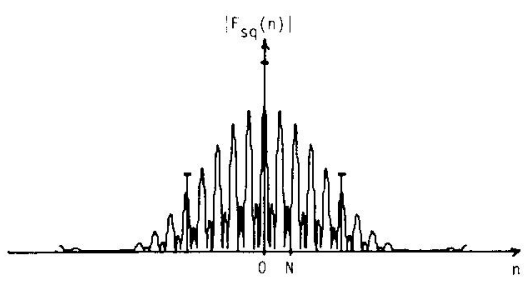

(b) (a)

$$
\begin{aligned}
& \text { (a) } p_{2}=0, p_{3}=3 \\
& \text { (b) } p_{2}=3, p_{3}=1
\end{aligned}
$$

The distortion is of course dependent on the actual sequence delays chosen, so to some extent the spectrum envelope may be shaped to a desired form by proper choice of delays.

\subsection{AUTOCORRELATION AND SPECTRUM OF $1.2 \mathrm{Gbit} / \mathrm{s}$ SEQUENCE}

The mutual delays of the six channels of the 1.2 Gbit/s generator were chosen so that the autocorrelation function had no peaks near 0 and no

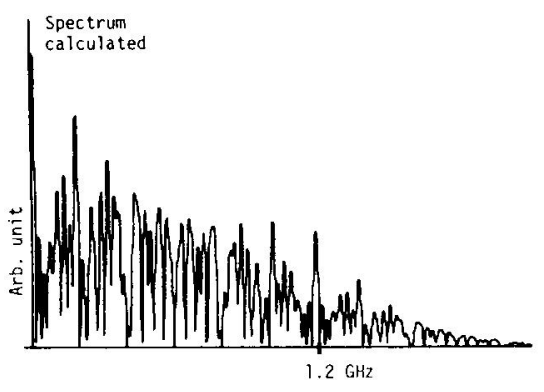

Fig. 12: Calculated sequence spectrum.

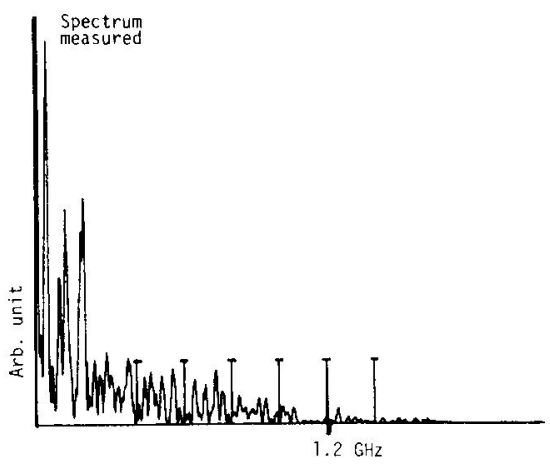

Fig. 13: Measured sequence spectrum. 
peak coincidences. With these restrictions the spectrum was shaped to the closest resemblance of a truly random sequence spectrum. Fig. 12 shows the calculated spectrum assuming triangular pulses and Fig. 13 shows the measured spectrum.

To some extent the two spectra are similar. Of course the measured spectrum is narrower than the theoretical one. The presence of the $200 \mathrm{MHz}$ clock frequency and its harmonics in the measured spectrum (these lines are not drawn to scale) is probably due to a not perfectly precise realization of the delays. The calculated spectrum shows that these components should be extinguished.

\section{CONCLUSION}

A $1.2 \mathrm{Gbit} / \mathrm{s}$ pseudo random pulse generator using multiplex of six 200 Mbit/s channels has been presented. A new, simple and very fast GaAsMESFET gate circuit has been shown.

The autocorrelation and spectral consequences of multiplexing have been discussed. The importance of choosing proper sequence delays when designing sequence generators using multiplexing has been demonstrated.

Due to the very high speed switching characteristics of GaAs-MESFETs the gate circuit presented should be applicable to higher bit rates than demonstrated here. The real advantage of MESFETs is perhaps first obtained in the integrated technique. But here GaAs MESFETs are somewhat inconvenient because of the level shift from gate to drain [7]. However, this difficulty can be overcome by the use of other transistors, for instance normally-off GaAs-MESFETs.

\section{REFERENCES}

[1] Bosch, G.B.: Gigabit Electronics. Proceedings of the 7th European Microwave Conference, 1977.

[2] MacWilliams, F.J., Sloane, J.A.: Pseudo-Random Sequences and Arrays. Proc. IEEE, Dec. 1976.

[3] Van Tuyl, R. et al.: $4 \mathrm{GHz}$ Frequency Division with GaAs ICs. Dig. Techn. Pap., 1977, ISSCC, p. 198.

[4] White, G.: Optical Modulation at High Information Rates. BSTJ, Oct. 1971.

[5] Russer, R., Gruber, J.: Hybrid integrierter Multiplex mit Speicherschaltdioden für den Gbit/s-Bereich. Wissenschaftliche Berichte AEG-Telefunken 48, 1975.

[6] Barabas, U. et al.: Diode Multiplexer in the Multi-Gbit/s Range. Electron. Letters, vol. 14, Feb. 1978.

[7] Van Tuyl, R., Liechti, C.: High Speed Integrated Logic with GaAs MESFETS. IEEE, Jour. Solid State Circuits, Oct. 1974.

[8] Beneking, w., Filensky, W.: The GaAs MESFET as a Pulse Regenerator in the Gigabit per Second Range. MTT-24, June 1976. 